\title{
Rollator use and functional outcome of geriatric rehabilitation
}

\author{
Lutz Vogt, PhD; ${ }^{{ }^{*}}$ Katrin Lucki, MA; ${ }^{1}$ Matthias Bach, $\mathrm{MD}^{\mathbf{2}}$ Winfried Banzer, MD, PhD ${ }^{\mathbf{1}}$ \\ ${ }^{1}$ Department of Sports Medicine, Goethe-University Frankfurt am Main, Frankfurt, Germany; ${ }^{2}$ Geriatrische Klinik, \\ St. Elisabethen-Krankenhaus Frankfurt am Main, Frankfurt, Germany
}

\begin{abstract}
In a quasi-experimental pre- and postdesign, we examined the effect of rollator use on functional rehabilitation outcome in geriatric patients. From a sample of 458 geriatric inpatients, we matched 30 subjects who were not using assistive devices in their everyday lives but received a wheeled walker at the time of hospital admission (first-time user group) according to their admission scores on three motor performance tests (Timed Up-and-Go, Five-Times-Sit-to-Stand, and Performance-Oriented Mobility Assessment-Balance) with 30 patients who were actively using rollators as their primary walking aid for at least 3 months (long-term user group) and 30 control subjects without walking-aid assistance. Measurements were repeated after the inpatient rehabilitation regimen. The Kruskal-Wallis test did not reveal significant group differences in rehabilitation progress. Controls and device users, regardless of walking-aid experience, demonstrated nearly comparable mobility, strength, and balance improvements. More than half of each cohort (controls, $n=22$; first-time, $n=17$; long-term, $n=$ 18) achieved functional gains in all three motor tests. The study showed that rollator assistance does not interfere with rehabilitation outcome and, to some extent, legitimates the prescription of assistive devices to improve confidence and restore or maintain motor ability at the highest possible level.
\end{abstract}

Key words: functional test, geriatric rehabilitation, impairment, independence, inpatient, motor performance, outcome evaluation, rollator, walking aid, wheeled walker.

\section{INTRODUCTION}

Ambulation assistive devices are increasingly used to prolong independent ambulation and participation in societal life [1]. Because of the benefits, assistive devices are also prescribed in geriatrics to enhance stability, facilitate independence, or increase safety and security [2]. At the same time, authors have assumed that the regular use of such devices could lessen mobility-related activities of daily living function [3].

Because healthcare professionals and insurers are challenged to establish effective rehabilitation interventions, research focuses on internal and external factors that may limit functional gain or impact on the overall rehabilitation response. Cognitive impairment [4-5], motivation [6], and depression [7-9] are discussed as possible obstacles in motor rehabilitation. Although a substantial amount of social money is spent and a significant number of geriatric patients use and/or receive wheeled walkers [1], even during inpatient rehabilitation, to our knowledge no literature reports on the rehabilitation outcome or the functional gains that device users can achieve during active rehabilitation. Therefore, the present study examines the effect of rollator use on functional rehabilitation outcome in geriatric patients. 


\section{METHODS}

\section{Study Groups and Matching Procedure}

The study included 908 elderly Caucasian inpatients consecutively admitted to a local geriatric rehabilitation clinic in the years 2006 and 2007. From 458 inpatients with full admission and discharge data sets, we selected 219. Selection criteria were at least 65 years of age; independently mobile; able to understand and follow study instructions; and able to perform the Timed "Up-and-Go" test (TUG), Five-Times-Sit-to-Stand Test (FTSST), and the Performance-Oriented Mobility Assessment-Balance (POMA-B). Patients with acute neurological impairment (acute stroke, Parkinson disease, paresis of lower limbs) or other severe physical or psychiatric illness (e.g., vestibular impairment, uncontrolled diabetes mellitus, acute myocardial infarction, substance abuse) were not included. For motor-performance baseline matching, we assigned the 219 inpatients to three study groups according to their rollator experience. Eighty-one geriatric inpatients who were not using assistive devices in their everyday lives but received a wheeled walker at the time of hospital admission (first-time user group) were matched with 63 patients actively using rollators indoors as well as outdoors as their primary walking aid for at least 3 months (long-term user group) and 75 control subjects without walking-aid assistance. We used standardized selection procedure to match each individual in the first-time user group with one individual in the long-term user and one in the control group, according to the three motor performance test scores. For matching, sample distributions of each of the three admission baseline scores of the firsttime user group were divided into three terciles (upper, middle, and lower). The obtained tercile "boundaries" were used to classify and match individuals of the longterm user and control group with individuals of the firsttime user group in the upper, middle, and lower tercile for each of the three motor performance tests. In other words, every individual in one group was tercile-matched with one individual in the two other groups on the basis of each of the three admission motor performance tests. As shown in the Table, the matching procedure resulted in three congruent baseline motor function cohorts of 30 geriatric inpatients each. Figure 1 illustrates the selection process. Rollators with four wheels (two guide rollers) were used for walker-assisted gait. Average Mini-Mental State Examination scores ranged from 24 to 27. The mean \pm standard deviation (SD) length of stay was $28.7 \pm$ 13.9 days. During rehabilitation, subjects participated on average in 12 sessions, 30 minutes each of physiotherapy; 6 sessions, 30 minutes each, of ergotherapy; and 13 sessions, at least 20 minutes each of ergometer exercises.

Table.

Matched group characteristics of first-time $(n=30)$, control $(n=30)$, and long-term $(n=30)$ groups according to motor performance tests (terciles of TUG, FTSST, and POMA-B test scores), number of subjects ( $n$ ), and age (years).

\begin{tabular}{|c|c|c|c|c|c|c|c|c|c|c|c|}
\hline \multicolumn{3}{|c|}{$\begin{array}{l}\text { Terciles of Motor } \\
\text { Performance Tests }\end{array}$} & \multicolumn{3}{|c|}{ First Time } & \multicolumn{3}{|c|}{ Control } & \multicolumn{3}{|c|}{ Long-Term } \\
\hline TUG & FTSST & POMA-B & M & $\mathrm{F}$ & Age & M & $\mathrm{F}$ & Age & M & $\mathrm{F}$ & Age \\
\hline U Upper & "Upper & Lower & 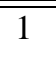 & 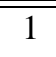 & 79,80 & $\overline{c 1}$ & $\overline{c 1}$ & 66,84 & 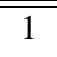 & 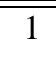 & "69,75 \\
\hline Upper & Middle & Lower & - & 2 & 83,84 & - & 2 & 78,89 & - & 2 & 82,87 \\
\hline Lower & Lower & Lower & - & 2 & 87,88 & - & 2 & 78,89 & - & 2 & 82,87 \\
\hline Upper & Upper & Middle & 1 & 3 & 73,94 & 1 & 3 & 78,88 & - & 4 & 77,86 \\
\hline Upper & Middle & Middle & - & 4 & 82,90 & 1 & 3 & 65,82 & 1 & 3 & 77,83 \\
\hline Middle & Middle & Middle & - & 3 & 69,83 & 1 & 2 & 87 & 1 & 2 & 70,80 \\
\hline Upper & Lower & Middle & - & 1 & 85 & - & 1 & 75 & - & 1 & 65 \\
\hline Lower & Lower & Middle & - & 2 & 72,88 & - & 2 & 74,80 & - & 2 & 74,80 \\
\hline Upper & Upper & Upper & 4 & 4 & 74,87 & 2 & 6 & 82,92 & 2 & 6 & 77,88 \\
\hline Middle & Upper & Upper & 1 & - & 78 & 1 & - & 72 & - & 1 & 85 \\
\hline Upper & Middle & Upper & 1 & - & 84 & 1 & - & 82 & 1 & - & 81 \\
\hline
\end{tabular}

F = female, FTSST = Five-Times-Sit-to-Stand Test, M = male, POMA-B = Performance-Oriented Mobility Assessment—Balance, TUG = Timed “Up-and-Go” test 


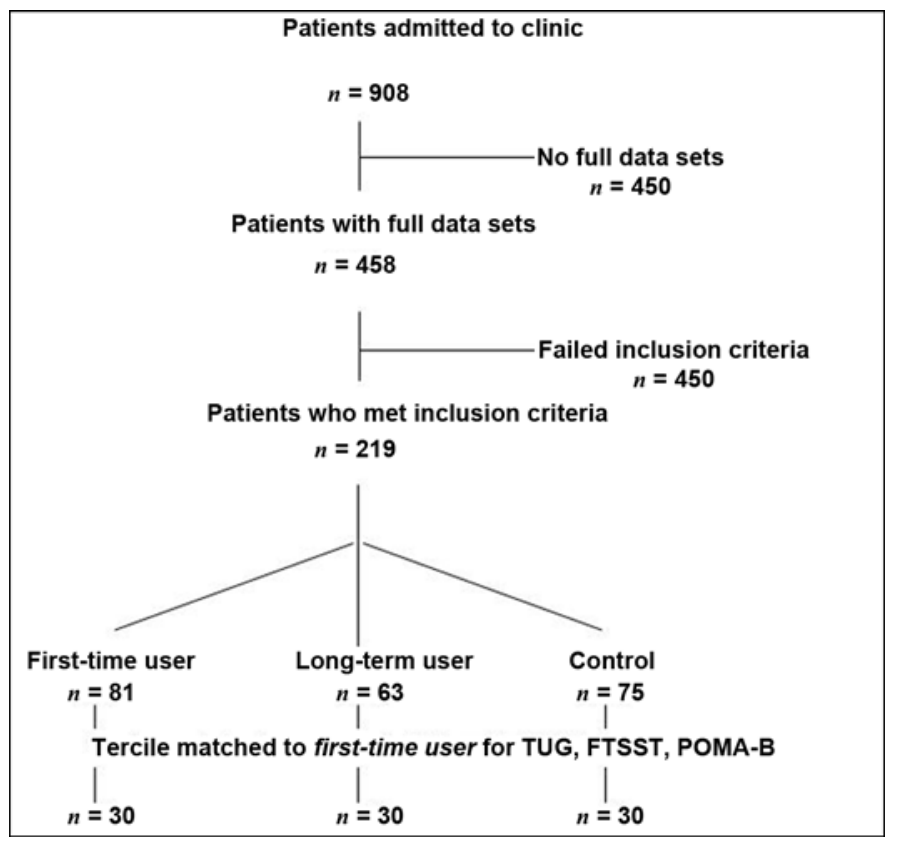

Figure 1.

Selection process flow chart of patients admitted to local geriatric rehabilitation clinic (2006-2007) who performed pre- and postmotor performance tests. FTSST = Five-Times-Sit-To-Stand, POMA-B = Performance-Oriented Mobility Assessment-Balance, TUG = Timed "Up-and-Go" test.

\section{Motor Performance Testing}

The three motor tests were carried out by experienced physiotherapists at the time of admission and rehabilitation discharge. We used the TUG, a valid and reliable screening procedure, to determine patients' functional mobility [10]. Subjects were timed while they stood up from a standard armchair without using the upper limbs, walked $3 \mathrm{~m}$, turned $180^{\circ}$, returned, and sat again. The participants were instructed to perform the TUG at their normal speed, and they performed one trial before they were timed. Device users were instructed to use their walking aid during test completion. Study participants who received a wheeled walker at the time of admission were given sufficient time to familiarize themselves with it so we would obtain valid information [11].

FTSST was used as a proxy measure of lower-limb strength and hip-surrounding muscle function [12-14]. The FTSST transfer requires that the individual exert forces with appropriate magnitude and timing. All subjects began by crossing their arms on their chests and sitting with their backs against the chairs. Subjects were allowed to place their feet comfortably under them during testing and instructed to stand up fully between repetitions of the test [15]. The time required to complete five repeated chair stands was determined. Sufficient reproducibility [16] and significant relationship with fall risk in older adults [17] have been demonstrated with the FTSST.

Balance capacity was rated by the POMA-B. Consisting of eight items, scored on a 2- or 3-point scale, and resulting in a maximum score of 15 , this subscale has also been identified as an independent predictor of future recurrent falls [18]. Interrater reliability for the POMA-B subscale was good to excellent across many raters of varied experience [19].

\section{Data Analysis and Statistical Methods}

For every motor test, we calculated the difference between admission and discharge scores at the individual level to assess and compare the intervention effect and the functional gain in mobility, strength, and balance between groups. We used nonparametric testing (KruskalWallis test) to determine differences in absolute rehabilitation gains and frequencies between groups. A level of significance was determined at 95 percent $(p<0.05)$.

\section{RESULTS}

Controls and device users, regardless of their walking aid experience, demonstrated nearly comparable mobility, strength, and balance improvements (Figure 2). Thus, a Kruskal-Wallis test did not reveal significant

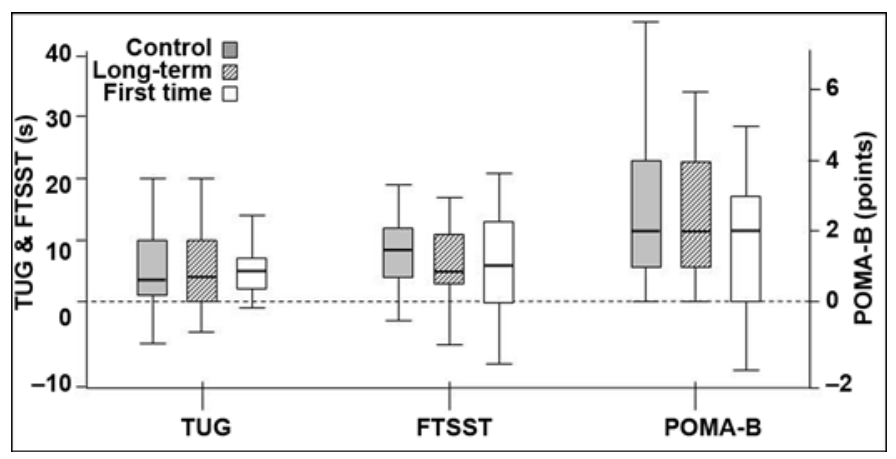

Figure 2.

Motor improvements in Timed “Up-and-Go" test (TUG), Five-Times-SitTo-Stand (FTSST), and Performance-Oriented Mobility Assessment (POMA-B) test scores during geriatric inpatient rehabilitation in relation to rollator use experience (minimum, maximum, median, interquartile range). 
group differences in rehabilitation progress. Categorical testing also demonstrated no significant discrepancy between the observed and expected frequencies, because more than half of each cohort (controls, $n=22$; first-time, $n=17$; long-term, $n=18$ ) achieved functional gains in all three motor tests. TUG subgroup analysis, with respect to the degree of functional dependence at discharge, indicated that two controls and four patients of the first-time and the long-term user groups needed 30 seconds or more for test completion.

\section{DISCUSSION}

In the present study, practically all geriatric patients, walker-assisted and unassisted alike, improved their motor capacity during rehabilitation and demonstrated enhanced abilities to perform functional activities or assist in self-care at discharge. The functional performance at baseline as well as the overall rehabilitation gain was comparable with findings of other authors [2023]. However, because of the TUG subgroup analysis, some geriatric patients may still require assistance for mobility tasks [10], irrespective of rollator usage. However, our study shows that rollator assistance does not interfere with functional gains and geriatric rehabilitation outcome, as seen in the almost comparable motor improvements of the treatment and control groups. Our findings underline the potential and, to some extent, legitimate the prescription of assistive devices in the rehabilitation of elderly persons with disabilities [2] to improve confidence and restore or maintain motor ability at the highest possible level [24].

Our findings also agree with Bateni and Maki, who stated that wheeled walkers can improve balance and mobility [25]. From this point of view, we raise the question of how far assistive devices, such as wheeled walker, should be regarded as compensatory measures for a loss of capacity [26]. Hoening et al. suggest that the use of equipment may help prevent induced disability or preserve physical conditioning by maintaining a greater level of physical activity, or its effect may be direct, by allowing self-care tasks to be performed more efficiently [27]. Although the available postfall documentation data of our present study cohort prevented hazard or fallsrelated testing, our findings raise the possibility that especially frail patients with greater need for supervision may benefit from wheeled walkers.
However, our retrospective study design makes the results not definitive, and from a methodological point of view, some shortcomings of our study have to be considered. Ignoring financial constraints and lack of information, one must consider awareness of the existence of assistive devices, positive device orientation, expectation of use, and availability as potential confounders of the present results. Especially in the long-term user group, several persons may not have had any underlying difficulty but instead were using their assistive device in a preventive fashion to feel a sense of security and avoid injuries, such as falls. In other words, the retrospective analysis was not able to clearly differentiate between patients who used and those who were in need of rollators before rehabilitation admission. Since a great proportion of subjects use equipment in combination with formal care [28], decisions about the use of technical assistance were likely to be made with consideration for a sense of security. In these patients, continuing use of wheeled walker over an extended time period could have also lessened mobility-related functioning, facilitated dependency in self-care (as suggested by Alkjaer et al. [3]), and influenced how people cope with disability.

\section{CONCLUSIONS}

Overall, the present study shows that rollators may be feasible substitutes for personal mobility-related activities and confidence enhancement during geriatric rehabilitation for a relatively moderate healthcare cost.

\section{ACKNOWLEDGMENTS}

Author Contributions:

Study concept and design: L. Vogt, K. Lucki.

Acquisition of data: M. Bach, K. Lucki.

Analysis and interpretation of data: L. Vogt, K. Lucki.

Drafting of manuscript: L. Vogt, K. Lucki.

Critical revision of manuscript for important intellectual content:

L. Vogt, K. Lucki, M. Bach, W. Banzer.

Statistical analysis: L. Vogt.

Obtained funding: M. Bach, W. Banzer.

Administrative, technical, or material support: M. Bach, W. Banzer.

Study supervision: L. Vogt, W. Banzer.

Financial Disclosures: The authors have declared that no competing interests exist.

Funding/Support: This work was unfunded at the time of manuscript preparation. 
Institutional Review: This study was approved by the local ethics committee of the Faculty of Psychology and Sport Sciences, GoetheUniversity Frankfurt am Main, Frankfurt, Germany.

Participant Follow-Up: The authors plan to inform participants of the publication of this study.

\section{REFERENCES}

1. Brandt A, Iwarsson S, Stahl A. Satisfaction with rollators among community-living users: A follow-up study. Disabil Rehabil. 2003;25(7):343-53. [PMID: 12745958]

DOI:10.1080/0963828021000058495

2. Häggblom-Kronlöf G, Sonn U. Use of assistive devicesA reality full of contradictions in elderly persons' everyday life. Disabil Rehabil Assist Technol. 2007;2(6):335-45. [PMID: 19263564$]$ DOI:10.1080/17483100701701672

3. Alkjaer T, Larsen PK, Pedersen G, Nielsen LH, Simonsen EB. Biomechanical analysis of rollator walking. Biomed Eng Online. 2006;5:2. [PMID: 16398933] DOI:10.1186/1475-925X-5-2

4. Goldstein FC, Strasser DC, Woodard JL, Roberts VJ. Functional outcome of cognitively impaired hip fracture patients on a geriatric rehabilitation unit. J Am Geriatr Soc. 1997; 45(1):35-42. [PMID: 8994485

5. Diamond PT, Felsenthal G, Macciocchi SN, Butler DH, Lally-Cassidy D. Effect of cognitive impairment on rehabilitation outcome. Am J Phys Med Rehabil. 1996; 75(1): 40-43. [PMID: 8645438] DOI:10.1097/00002060-199601000-00011

6. Resnick B. Geriatric rehabilitation: The influence of efficacy beliefs and motivation. Rehabil Nurs. 2002;27(4): 152-59. [PMID: 12116528]

7. Harris RE, Mion LC, Patterson MB, Frengley JD. Severe illness in older patients: The association between depressive disorders and functional dependency during the recovery phase. J Am Geriatr Soc. 1988;36(10):890-96.

[PMID: 3171028$]$

8. Diamond PT, Holroyd S, Macciocchi SN, Felsenthal G. Prevalence of depression and outcome on the geriatric rehabilitation unit. Am J Phys Med Rehabil. 1995;74(3): 214-17. [PMID: 7779332] DOI:10.1097/00002060-199505000-00006

9. Slaets JP, Kaufmann RH, Duivenvoorden HJ, Pelemans W, Schudel WJ. A randomized trial of geriatric liaison intervention in elderly medical inpatients. Psychosom Med. 1997;59(6):585-91. [PMID: 9407576]

10. Podsiadlo D, Richardson S. The timed “Up \& Go”: A test of basic functional mobility for frail elderly persons. J Am Geriatr Soc. 1991;39(2):142-48. [PMID: 1991946]
11. Lucki K, Bach M, Banzer W, Vogt L. Walker use affects Timed Up and Go and gait speed measures. J Am Geriatr Soc. 2009;57(10):1963-65. [PMID: 19807815] DOI:10.1111/j.1532-5415.2009.02475.X

12. Schenkman M, Hughes MA, Samsa G, Studenski S. The relative importance of strength and balance in chair rise by functionally impaired older individuals. J Am Geriatr Soc. 1996;44(12):1441-46. [PMID: 8951313]

13. Chandler JM, Duncan PW, Kochersberger G, Studenski S. Is lower extremity strength gain associated with improvement in physical performance and disability in frail, communitydwelling elders? Arch Phys Med Rehabil. 1998;79(1):24-30. [PMID: 9440412] DOI:10.1016/S0003-9993(98)90202-7

14. Runge M, Hunter G. Determinants of musculoskeletal frailty and the risk of falls in old age. J Musculoskelet Neuronal Interact. 2006;6(2):167-73. [PMID: 16849828]

15. Whitney SL, Wrisley DM, Marchetti GF, Gee MA, Redfern MS, Furman JM. Clinical measurement of sit-to-stand performance in people with balance disorders: Validity of data for the Five-Times-Sit-to-Stand Test. Phys Ther. 2005; 85(10):1034-45. [PMID: 16180952]

16. Lord SR, Murray SM, Chapman K, Munro B, Tiedemann A. Sit-to-stand performance depends on sensation, speed, balance, and psychological status in addition to strength in older people. J Gerontol A Biol Sci Med Sci. 2002;57(8): M539-43. [PMID: 12145369]

17. Tromp AM, Pluijm SM, Smit JH, Deeg DJ, Bouter LM, Lips P. Fall-risk screening test: A prospective study on predictors for falls in community-dwelling elderly. J Clin Epidemiol. 2001;54(8):837-44. [PMID: 11470394] DOI:10.1016/S0895-4356(01)00349-3

18. Thapa PB, Gideon P, Brockman KG, Fought RL, Ray WA. Clinical and biomechanical measures of balance as fall predictors in ambulatory nursing home residents. J Gerontol. A Biol Sci Med Sci. 1996;51(5):M239-46. [PMID: 8808996]

19. Cipriany-Dacko LM, Innerst D, Johannsen J, Rude V. Interrater reliability of the Tinetti Balance Scores in novice and experienced physical therapy clinicians. Arch Phys Med Rehabil. 1997;78(10):1160-64. [PMID: 9339170] DOI:10.1016/S0003-9993(97)90145-3

20. Hauer K, Pfisterer M, Schuler M, Bärtsch P, Oster P. Two years later: A prospective long-term follow-up of a training intervention in geriatric patients with a history of severe falls. Arch Phys Med Rehabil. 2003;84(10):1426-32.

[PMID: 14586908] DOI:10.1016/S0003-9993(03)00267-3

21. Newton RA. Balance screening of an inner city older adult population. Arch Phys Med Rehabil. 1997;78(6):587-91. [PMID: 9196465] DOI:10.1016/S0003-9993(97)90423-8 
22. Nordin E, Rosendahl E, Lundin-Olsson L. Timed "Up \& Go" test: Reliability in older people dependent in activities of daily living - Focus on cognitive state. Phys Ther. 2006; 86(5):646-55. [PMID: 16649889]

23. Nordin E, Lindelöf N, Rosendahl E, Jensen J, LundinOlsson L. Prognostic validity of the Timed Up-and-Go test, a modified Get-Up-and-Go test, staff's global judgement and fall history in evaluating fall risk in residential care facilities. Age Ageing. 2008;37(4):442-48. [PMID: 18515291] DOI:10.1093/ageing/afn101

24. Balash Y, Hadar-Frumer M, Herman T, Peretz C, Giladi N, Hausdorff JM. The effects of reducing fear of falling on locomotion in older adults with a higher level gait disorder. J Neural Transm. 2007;114(10):1309-14. [PMID: 17576513] DOI:10.1007/s00702-007-0771-z

25. Bateni H, Maki BE. Assistive devices for balance and mobility: Benefits, demands, and adverse consequences. Arch Phys Med Rehabil. 2005;86(1):134-45.
[PMID: 15641004$]$

DOI:10.1016/j.apmr.2004.04.023

26. Mahoney JE, Sager MA, Jalaluddin M. Use of an ambulation assistive device predicts functional decline associated with hospitalization. J Gerontol A Biol Sci Med Sci. 1999; 54(2):M83-88. [PMID: 10051860]

27. Hoenig H, Taylor DH, Sloan FA. Does assistive technology substitute for personal assistance among the disabled elderly? Am J Public Health. 2003;93(2):330-37. [PMID: 12554595] DOI:10.2105/AJPH.93.2.330

28. Agree EM, Freedman VA. Incorporating assistive devices into community-based long-term care: An analysis of the potential for substitution and supplementation. J Aging Health. 2000;12(3):426-50. [PMID: 11067703] DOI:10.1177/089826430001200307

Submitted for publication September 11, 2009. Accepted in revised form December 17, 2009. 